\title{
Penilaian Kinerja Perusahaan \\ Melalui Pendekatan "Economic Value Added" Suatu Paradigma Baru
}

\section{Oleh : Indarto Waluyo}

\section{ABSTRAK}

Dalam beberapa tahun terakhir Indek Harga Saham Gabungan (IHSG) dan Kapitalisasi pasar di Bursa Efek Jakarta menunjukkan angka yang cukup berarti bila dibanding dengan tahun tahun sebelumnya, ini menunjukkan bahwa pasar modal mempunyai daya tarik tersendiri bagi para investor dewasa ini. Dengan semakin maraknya investor "bermain" di pasar modal, tentunya kompetisi menjadi semakin tajam, dengan semakin tajamnya kompetisi maka diperlukan alat yang lebih akurat dalam mengevaluasi tingkat hasil yang akan diperoleh. Sampai dengan tahun 90-an, alat yang digunakan oleh para investor dalam menilai "kelayakan" investasi merreka adalah ROI (return on investment) dan RI (residual income).

Tetapi dalam kenyataannya alat penilai ini banyak mengalami bias. Karena hasil analisanya bias maka mengakibatkan keputusan yang diambil oleh para investor mengalami distorsi. Berdasar pengalaman tersebut maka akhir-akhir ini muncul alat penilai investasi baru yang merupakan penyempurnaan dari alat ukur sebelumina, yakni yang dikenal dengan nama EVA (Economic Value Added). Keistimewan alat ini adalah tidak hanya semata-mata

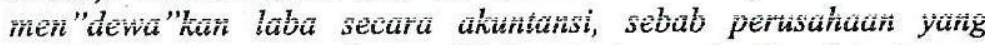
meraih untung secara akuntansi belum tentu memberikan keuntungan bagi pemiliknya atau para pemegang sahamnya. Disamping itu alat penilai ini bisa juga digunakan oleh para komisaris untuk menentuḱkan berapa kompensasi yang akan diberikan kepada manajemen atas kinerjanya selama ini.

\section{Pendahuluan}

Pertumbuhan ekonomi Indonesia pada tahun 2002 lalu mencapai angka 3.66 persen. Angka pertumbuhan ini tidak saja menambah deretan indikator makro yang menggambarkan lebih baiknya perekonomian tahun 2002, tetapi menunjukkan juga bahwa dampak tragedi bom Bali dapat

diminimalisasi, sehingga tidak perlu mengurangi pertumbuhan ekonomi nasional. Meskipun pertumbuhan ckonomi pada triwulan kekempat 2002 tercatat mengalami penurunan rekitar 2.6 persen dibandingkan

dengan triwulan sebelumnya namun hal ini merupakan pola musiman yang selalu terjadi. Namun secara garis besar indikator makro kita tahun 2002 berada pada tingkat yang relatif baik.

Data Ekonomi Makro (Perbankan dan Pasar Modal)

\begin{tabular}{|c|l|r|r|r|}
\hline No & \multicolumn{1}{|c|}{ Item } & \multicolumn{3}{c|}{ Tahun } \\
\cline { 3 - 5 } & & \multicolumn{1}{c|}{2000} & \multicolumn{1}{c|}{2001} & \multicolumn{1}{c|}{2002} \\
\hline 2 & Kurs Tengah Rp/US S & 9.595 & 10.400 & 8.940 \\
\hline 3 & Inflasi (\%) & 9,35 & 12,55 & 10,03 \\
\hline 4 & Uang primer beredar (triliun) & 125,6 & 127,8 & 138,3 \\
\hline 5 & Dana Perbankan (triliun) & 720,4 & 809,1 & 845,0 \\
\hline 6 & Kredit Perbankan (triliun) & 269,0 & 307,6 & 365,4 \\
\hline & Suku bunga deposito 1 bln (\%) & & & \\
\hline & Bank Pemerintah & 11,43 & 16,59 & 12,84 \\
\hline 7 & Bank Swasta Nasional & 11,09 & 15,83 & 12,90 \\
\hline 8 & Suku bunga SBI 1 bln (\%) & 14,53 & 17,62 & 12,93 \\
\cline { 2 - 5 } & Suku bunga Kredit Rupiah (\%) & & & \\
\hline & Kredit Modal Kerja & 18,43 & 19,19 & 18,25 \\
\hline 9 & Kredit Investasi & 16,59 & 17,90 & 17,82 \\
\hline 10 & IHSG Bursa Efek Jakarta & 416,3 & 392,0 & 424,9 \\
\hline & Kapitalisasi Pasar (Triliun) & 259,6 & 239,3 & 268,4 \\
\hline
\end{tabular}

aumber : (Jurnal. Míarei. 2003)

Dalam data terlihat Indek Ilarga Saham Gabungan (IHSG) dan Kapitalisasi pasar pada tahun 2002 menunjukkan angka yang cukup berasti bila dibanding dengan tahun taliun scbelumnya, ini menunjukkan bahwa pasar modal mempunya daya larik tersendiri bagi para investor dewasa ini. Dengan iemakin maraknya investor "bermain" di pasar modal, tentunya kompctisi menjadi semakin tajam, dengan semakin tajamnya kompetisi maka diperiukan alat yang lebih akurat dalam mengevaluasi tingkat hasil yang akan diperoleh. Sampai dengan tahun 90-an, alat yang digunakan oleh para investor daiam menilai "kelayakan" investasi mereka adalah ROI (return on investment) dan RI (residual income).

Tetapi dalam kenyataannya alat penilai ini banyak mengalami bias. Karena hasil analisanya bias maka mengakibatkan keputusan 
yang diambil oleh para investor keseluruhan dana yang ditanamkan mengalami distorsi. Berdasar dalam aktiva yang digunakan dalam pengalaman tersebut maka akhir- operasi perusahaan untuk akhir ini muncul alat penilai menghasilkan keuntungan investasi baru yang merupakan (Munawir:2001). Dengan demikian penyempurnaan dari alat ukur rasio ini menggabungkan sebelumnya, yakni yang dikenal keuntungan yang diperoleh dari dengan nama EVA (Economic Value operasi perusahaan dengan jumlah Added). Keistimewaan alat ini investasi atau aktiva yang adalah tidak hanya semata-mata digunakian untuk menghasilkan men"dewa"kan laba secara keuntungan tersebut. Besarnya ROI akuntansi, sebab perusahaan yang dipengaruhi oleh dua faktor:

meraih untung secara akuntansi

belum tentu memberikan keuntungan bagi pemiliknya atau para pemegang sahamnya.

Disamping itu alat penilai ini bisa juga digunakan oleh para komisaris untuk menentukan berapa

kompensasi yang akan diberikan kepada manajemen atas kinerjanya selama ini.

\section{Pengertian}

ROI (return on investment) adalah rasio profitabilitas yang dimaksudkan uniuk mengukur kemampuan perusahaan dengan

- Turnover dari operating assets (tingkat perputaran aktiva yang digunakan untuk operasi)

- Profit margin, besarnya keuntungan operasi yang dinyatakan dalam prosentase dan jumlah penjualan bersih Proñit margin ini mengukur tingkat keuntungan yang dapa dicapai oleh perusahaan dihubungkan dengan penjualannnya (Munawir :2001)

Kedua faktor tersebut dapat diformulasikan sebagai beriktit

Penjualan $\frac{\text { Laba Usaha }}{\text { Operating Asset }} \times \frac{\text { Penjualan }}{}$

Sedangkan RI (Residual : 1991). Residual income atau laba Income) dihitung dengan cara residu dinyatakan dalam mata uang, mengurangkan biaya modal dari laba jadi bukan rasio.

Untuk lebih jelasnya diperlihatkan dibawah ini contohnya:

\section{Perusahaan HARJUNA}

\section{Neraca per 31 Desember 19xx}

\section{AKTIVA LANCAR}

\section{Kas $\quad 25.000$}

Piliutang dagang 75.000

Barang dagang 200.000

Jumlah Aktv Lancar $\underline{\underline{300.000}}$

\section{AKTIVA TETAP}

Mesin (netto) 250.000

Bangunan (netto) 350.000

Tanah $\quad 100.000$

Jumlah Aktv Tetap

Jumlah Aktiva $\quad 1.000 .000$

Laporan Laba - Rugi periode 19xx

Penjualan netto

llarga Pokok Penjualan

Laba bruto

\subsection{0 .000}

1.000 .000

1.000 .000

Niaya administrasi

Diaya penjualan

II:ays umum

Iotal biaya

Laba operasi (usaha)

Ilunga

Laba scbclum pajak

\section{HUTANG LANCAR}

Hutang dagang

Hutang wessel

25.000

9.000

Jumlah Hutang Lancar 255.000

\section{HTANG JK PANJANG}

Modal sendiri :

Saham + Laba dithn $\quad \underline{565.000}$
250.000

150.000

700.000

300.000

9.000

291.000 


\section{$\underline{145.000}$}

Laba setelah pajak

Sumber : (Munawir:2001)

Dari data tersebut dapat diperoleh hasil perhitungan sebagai berikut :

- Return on investment

$=$ penjualan

Operating asset

$=2.000 .000$

1.00 .0

$=30 \%$

- Residual income

$=$ laba usaha - beban bunga

$=300.000-9.000$

$=$ Rp. 291.000 ,-

Economic Value Added (EVA) adalah suatu alat pengukuran kinerja perusahaan yang menilai berhasil tidaknya suatu kegiatan / aktivitas dari sudut kepentingan dan harapan penyandang dana (kreditur dan pemegang saham). Jika EVA > 0 maka telah terjadi proses nilai tambahi pauda perusahaañ. Ecoñomic Value Added dianggap mampu mempermudah tugas-tugas komisaris dalam melakukan bergainning dengan manajemen. Sebab perusahaan yang mampu meraih untung secara akuntansi belum tentu memberikan
146.000

$$
\mathrm{X} \text { laba usaha }
$$

penjualan

$$
300.000
$$

2.000 .000 keuntungan bagi pemiliknya atau para pemegang saham

Untuk dapat menghitung EVA maka langkah-langkah yang harus dilalui adalah sebagai berikut (Fakhrudin, Arifin : 1909)

a. Menghitung cost of debt (biaya modal yang berasal uari huitañg)

b. Menghitung cost of equity (biaya modal yang berasal dari saham)

c. Menghitung struktur permodalan

d. Menghitung biaya modal tertimbang e. Menghitung economic value added

\section{Pembanding ROI \& RI versu} EYA

Dalam penilitian yang dilakukan oleh James S.Reece dan William R. Cool terhadap 1.000 perusahaan, $96 \%$ dari responden atau 594 perusahaan mempunyai pusat laba atau pusat investasi. Pusat laba digunakan oleh 185 (23\%) dan pusat investasi oleh 459 (77\%). Diantara perusahaan yang menggunakan pusat investasi. $65 \%$ mengevaluasinya dengan ROI saja, $28 \%$ dengan ROI dan RI. Hanya $2 \%$ yang menggunakan RI.(James and William:Harvard Business Review : 1978).

Namun dalam era 90-an, ada pergeseran model pengukuran yakni dengan adanya model EVA. Pengukuran kinerja perusahaan menggunakan model economic value added merupakan suatu terobosan baru dalam manajemen keuangan. Saat ini, khususnya di negara maju seperti Amerika Serikat, metode pengukuran kinerja dengan EVA sangat digandrungi. Jurnal Financial Management memuji metode ini karena mampu membuat para manajer "bertinđak seperti pemiliknya". Para eksekutif dan manajer perusahaan dituntut untuk mampu menghasilkan keuntungan dari operasi perusahaan. Berikut dibawah ini diberikan contoh penerapan ketiga model tersebut :

\section{PT. Sandy Multi Informatika}

\begin{tabular}{|c|c|c|c|c|c|}
\hline \multirow[t]{2}{*}{ AKTIVA } & \multicolumn{2}{|c|}{ Tahun } & \multirow[t]{2}{*}{ IPASSIVA } & \multicolumn{2}{|c|}{ Tahun } \\
\hline & 1993 & 1994 & & 1993 & 1994 \\
\hline Kas dan Bank & 2.200 & 2.000 & Hutang J.Pendk & 2.600 & 60 \\
\hline Piutang & 6.500 & 6.260 & Hutang pd Pemasok & 3.550 & 300 \\
\hline Persediaan & 4.350 & 4.500 & & & \\
\hline Jumlah Ahtiva Lanicar & 13.050 & 12.760 & Kewajiban I Pendek & 6.150 & 360 \\
\hline Aktiva Tetap & 4.000 & 5.000 & Hutang J.Panjang & 3.800 & 5.400 \\
\hline & & & Modal Sendiri & 7.100 & 12.000 \\
\hline Iotal Aktiva & 17.050 & 17.760 & Total Pasiva & 17.050 & 17.760 \\
\hline
\end{tabular}

Neraca 
PT. Sandy Multi Informatika

\begin{tabular}{|c|c|c|}
\hline \multirow[t]{2}{*}{ Item } & \multicolumn{2}{|c|}{ Tahun } \\
\hline & 1993 & 1994 \\
\hline Penjualan Bersih & 32.500 & 35.000 \\
\hline Harga Pokok Penjualan $(40 \%)$ & 13.000 & 14.000 \\
\hline Laba Kotor & 19.500 & 21.000 \\
\hline Biaya Operasional $(10 \%)$ & 3.250 & 3.5 .00 \\
\hline Beban Bunga $(17 \%)$ & $\cdot 646$ & 918 \\
\hline Laba sebelum pajak & 15.604 & 16.582 \\
\hline Pajak Perusahaan $(15 \%)$ & 1.560 & 1.658 \\
\hline Laba setelah pajak & 14.044 & 14.924 \\
\hline Koefisien Beta & 1,3 & 1,3 \\
\hline
\end{tabular}

Apabila kita mengukur kinerja PT. Sandy Multi Informatika dengan model pendekatan lama (ROI dan RI) maka akan diperoleh hasil sebagai berikut

a. ROI (Return on investment) penjualan

laba usaha

Opetating asset

Operating asset

penjualan

- Tahun 1995

$=32.500$

17.050

$=95 \%$

- Tahun 1994

$=35.000$

\begin{abstract}
$-$
\end{abstract}
17.060

$=99 \%$
21.000

19.500

$\mathrm{X}$

32.500

35.000

b. RI (Residual income)

laba usaha - beban bunga

- Tahun 1993

$=16.250-646$

$=\mathrm{Rp} .15 .604,-$

- Tahun 1994

$=17.500-918$

$=\mathrm{Rp} \cdot 16.582$,-

c. EVA (Economic value added)

Untuk menentukan besarnya EVA maka harus dilalui beberapa tahap sebagai berikut :

- Menghitung cost of debt (biaya modal yang berasal dari hutang)

\begin{tabular}{|c|c|c|}
\hline \multirow[t]{2}{*}{ Item } & \multicolumn{2}{|c|}{ Tahun } \\
\hline & 1993 & 1994 \\
\hline Beban bunga & 646 & 918 \\
\hline Jumlah Ht Jk. Pnj & 3.800 & 5.400 \\
\hline Bunga & $17,0 \%$ & $17,0 \%$ \\
\hline Tingkat Pajak (p) & $15 \%$ & $15 \%$ \\
\hline Faktor Koreksi (1-p) & $85 \%$ & $85 \%$ \\
\hline Ongkos Modal Hutang (kD) & $14,5 \%$ & $14,5 \%$ \\
\hline
\end{tabular}

- Menghitung cost of equity (biaya modal yang berasal dari saham)

\begin{tabular}{||l|r|r|}
\hline \multirow{2}{*}{ Item } & \multicolumn{2}{|c|}{ Tahun } \\
\cline { 2 - 3 } & \multicolumn{1}{|c|}{1993} & 1994 \\
\hline $\mathrm{ff}$ (tanpa resiko) & $11,0 \%$ & $11,0 \%$ \\
\hline Beta & 1,3 & 1,3 \\
\hline $\mathrm{r}$ m(tingkat bunga pasar) & $20,0 \%$ & $20,0 \%$ \\
\hline Ongkos Modal Saham $(k E)$ & $22,7 \%$ & $22,7 \%$ \\
\hline
\end{tabular}




\section{- Menghitung struktur permodalan}

\begin{tabular}{||l|r|r|}
\hline \multicolumn{1}{|c|}{ Item } & \multicolumn{2}{|c|}{ Tahin } \\
\cline { 2 - 3 } & \multicolumn{199}{|c|}{$\mathbf{1 9 9 3}$} & $\mathbf{1 9 9 4}$ \\
\hline Hutang Jk Pjng & 3.800 & 5.400 \\
\hline Modal Saham & 7.100 & 12.000 \\
\hline Jumlah Modal & 10.900 & 17.400 \\
\hline Komposisi Hutang & $35 \%$ & $31 \%$ \\
\hline Komposisi Modal Saham & $65 \%$ & $6 . \cdots$ \\
\hline
\end{tabular}

- Menghitung biaya modal tertimbang (weighted average cost of capital)

\begin{tabular}{||l|r|r|}
\hline \multirow{2}{*}{ Item } & \multicolumn{2}{|c|}{ Tahun } \\
\cline { 2 - 3 } & \multicolumn{1993}{|c|}{$\mathbf{1 9 9 4}$} \\
\hline WACC & $19,8 \%$ & $20,1 \%$ \\
\hline
\end{tabular}

- Menghitung economic value added

\begin{tabular}{||l|r|r|}
\hline \multicolumn{1}{|c|}{ Item } & \multicolumn{2}{|c|}{ Tahun } \\
\cline { 2 - 3 } & 1993 & 1994 \\
\hline Laba sblm Pajak & 15.604 & 16.582 \\
\hline Beban Bunga & 646 & 918 \\
\hline Laba sblm Bunga \& Pajak & 16.250 & 17.500 \\
\hline Beban Pajak & 6.500 & 7.000 \\
\hline Ongkos Modal Tertimbang & 2.161 & 3.504 \\
\hline Economic Value Added & 7.589 & 6.996 \\
\hline
\end{tabular}

Untuk lebin jelasniya hasil pemakaiañ ketiga alât peniläi teiseubut, tabel dibawah ini merangkum hasil akhirnya :

Majalah Imformasi
Tabel hasil perhitungan

Pendekatan ROI, RI, EVA

\begin{tabular}{||l|r|r|}
\hline \multirow{2}{*}{} & \multicolumn{2}{|c|}{ Tahun } \\
\cline { 2 - 3 } & 93 & \multicolumn{1}{|c|}{$\mathbf{9 4}$} \\
\hline ROI & $95 \%$ & $99 \%$ \\
\hline RI & 15.604 & 16.582 \\
\hline EVA & 7.589 & 6.996 \\
\hline
\end{tabular}

Dari data dalam tabel dapat terlihat bahwa dengan pendekatan ROI (return on investment) kinerja perusahaan tahun 1994 lebih baik bila dibandingkan dengan tahun sebelumnya yakni tahun 1993, hal ini dapat ditunjukkan dengan hasil akhir perhitungan pada tahun 1994 adalah 99\% sedangkan tahun 1993 lanya 95\%. Dengan pendekatan RI (residual income) hasil yang diperoleh tidak jauh berbeda dengan pendekatan ROI, yakni tahun 1994 perusahaan mampu mencetak laba residu Rp. 16.582,-- sedangkan tahun 1093 banya mampu membukukan laba Rp. 15.604,--. Secara garis besar pendekatan ROI dan RI menunjukkan bahwa tahun 1994, kinerja perusahaan cukup bagus bila dibandingkan dengan tahun sebelumnya.

Namun, dengan pendekatan IVA (economic value added) hasil perhitungan yang diperoleh akan berbeda dengan kedua pendekatan sebelumnya, karena pada tahun 1993 IVA-nya adalah Rp. 7.589,-; sedangkan tahun 1994 hanya Rp. 6.996," Kenapa muncul perbedaan

hasil perhitungan yang sangat berlawanan?. Faktor utamanya adalah dalam pendekatan ROI dan RI, semua aktiva dilibatkan dalam perhitungan (mengacu prinsip dasar akuntansi : aktiva = pasiva) sedangkan dalam pendekatan EVA berpijak pada sisi pasiva yang ada "biayanya", saja, yakni hutang jangka panjang (bunga) dan saham (deviden)., sedangkan hutang jangka pendek yang "relatif" tidak adanya biayanya (seperti hutang dagang, hutang wesel, hutang pada pemasok, dsb) tidak ikut dimasukkan dalam perhitungan. Sehingga ketika perusahaan menggganti utang jangka pendeknya dengan tambahan utang jangka panjang atau tambahan modal, akan sangat memperburuk hasil yang diperoleh bila menggunakan pendekatan EVA, karena dengan tambahan utang jangka panjang tersebut, beban perusahaan akan semakin besar karena harus menambah anggaran untuk pembayaran biaya bunga. 
Simpulan

Dalam beberapa tahun terakhir Indek Harga Saham Gabungan (IHSG) dan Kapitalisasi pasar di Bursa Efek Jakarta menunjukkan angka yang cukup berarti bila dibanding dengan tahuntahun sebelumnya, ini menunjukkan bahwa pasar modal mempunyai daya tarik tersendiri bagi para investor dewasa ini. Dengan semakin maraknya investor "bermain" di pasar modal, tentunya kompetisi menjadi semakin tajam, dengan semakin tajamnya kompetisi maka diperlukan alat yang lebih akurat dalam mengevaluasi tingkat hasil yang akan diperoleh. Sampai dengan tahun 90-an, alat yang digunakan oleh para investor dalam menilai "kclayakan" investasi mereka adalah ROI (return on investment) dan RI (residual income).

Tetapi dalam kenyataannya alat penilai ini banyak mengalami bias. Karena hasil analisanya bias maka mengakibatkan keputusan yang diambil oleh para investor mengalami distorsi. Berdasar pengalaman tersebut maka akhirakhir ini muncul alat penilai investasi baru yang merupakan penyempurnaan dari alat ukur sebelumnya, yakni yang dikenal dengan nama EVA (Economic Value Added $)$. Keistimewaan alat ini adalah tidak hanya semata-mata men"dewa"kan laba secara akuntansi, sebab perusahaan yang meraih untung secara akuntansi belum tentu memberikan keuntungan bagi pemiliknya atau para pemegang sahamnya. Disamping itu alat penilai ini bisa juga digunakan oleh para komisaris untuk menentukan berapa kompensasi yang akan diberikan kepada manajemen atas kinerjanya selama ini.

Dalam pendekatan ROI dan RI , semua aktiva dilibatkan dalam perhitungan (mengacu prinsip dasar akuntansi : aktiva = pasiva), sedangkan dalam pendekatan EVA berpijak pada sis pasiva yang ada "biayanya" saja, yakni hutang jangka panjang (bunga) dan saham (deviden). sedangkan hutang jangka pendel yang "relatif" tidak adanya biayanya (seperti hutang dagang, hutang wesel, hutang pada pemasok , dsb) tidak ikut dimasukkan dalam perhitungan. Sehingga ketika perusahaan menggganti utang jangka pendeknya dengan tambahan utang jangka panjang atau tambahan modal, akan sangat memperburuk hasil yang diperoleh bila menggunakan pendekatan EVA karena dengan tambahan utang jangka panjang tersebut, beban perusahaan akan semakin besar karena harus menambah anggaran untuk pembayaran biaya bunga.

\section{Daftar Pustaka}

Anthony Robert, Dearden John, Bedford Norton.1991

Management Control Systems.Richard

D.Irwin.Inc.

Fakhruddin Muhammad, Arifin Johar.1999. Analisis Bisnis Terpadu .... Jakarta. Elex Media Komputindo.

Hanafi Mamduh, Halim Abdul. 2000. Analisis Laporan

Keuangan.

Yogyakarta.UPP

AMP YKPN.

Munawir,Slamet.2001. Analisa Laporan Keuangan. Yogyakarta. Liberty.

Saenudin, Adhie.1996. Keuangan \&Bisnis.... . Yogyakarta. Andi.

-,Maret 2003. Minat investor....... dalam majalah Jurnal 2003.

,Maret 2003. Konsumsi Penggerak ....... dalam majalah Jurnal 2003.

\section{Biodata Penulis}

Indarto Waluyo, lulus dari jurusan Akuntansi Fakultas Ekonomi Universitas Gadjah Mada tahun 1996. Tahun 1996 s/d 1998 sebagai staff akuntansi PT.Wijaya Karya (Persero) kantor pusat Jakarta.Tahun 1998 s/d 1999 sebagai Kepala seksi akuntansi \& keuangan PT. Sedjahtera Industrial Co.Ltd Jakarta.Tahun $1999 \mathrm{~s} / \mathrm{d}$ sekarang sebagai pengajar di prodi Pendidikan Âkuntansi \& prodi Diploma Akuntansi Fakultas Ilmu Sosial (FE) UNY. Selain itu penulis aktif pula di beberapa institusi pengembangan UKM (usaha kecil dan menengah) seperti AKIP-KM (Asosiasi Konsultan Industri \& Perdagangan Kecil dan Menengah) DIY sebagai Human Resource Development, SMEDC-UGM (Small and Medium Enterprise Development Center s/d 2002) sebagai Supervisor Consultant, PT.Permodalan Nasional Madąni (Persero) sebagai Project Consultant. 